\title{
Maternal deprivation and the development of stereotypic behaviour
}

\author{
Naomi R. Latham ${ }^{\text {a,* }}$, G.J. Mason ${ }^{\mathrm{b}}$ \\ ${ }^{a}$ Zoology Department, South Parks Road, Oxford OX1 3PS, UK \\ ${ }^{\mathrm{b}}$ Department of Animal and Poultry Science, University of Guelph, Ontario, Canada N1G 2WI
}

Accepted 2 March 2007

Available online 29 May 2007

\begin{abstract}
Many farm, laboratory, zoo and companion animals experience some form of maternal deprivation. This is typically via separation from their mothers earlier than would happen in free-living populations, in some cases even while young are still dependent upon milk. Maternal deprivation may also occur in a qualitative way, via inadequate maternal care, perhaps caused by inexperience or by restrictive environments that limit maternal behaviours. In this paper we review evidence on the link between early separation from the mother and abnormal behaviour from a wide range of sources, including the early primate studies in this field, more recent examples from zoo and commercially reared animals, and human examples from studies of institutionalised children. We discuss factors that seem to influence the magnitude of later effects, such as developmental stage and age at separation, and whether separation is gradual (i.e. more similar to natural separation) or abrupt (as often the case in captivity). In these instances, however, maternal deprivation is just one aspect of a suite of changes that occur when infants are separated from their mothers. In the second part of the paper we therefore review the few cases where maternal loss per se has been investigated, and studies showing lasting affects of qualitative aspects of maternal care. We then look at the possible mechanisms underlying maternal deprivation-induced stereotypic behaviours including potential frustration of specific motivations, and lasting, more pervasive changes for instance in temperament or motor control. Finally, we discuss the practical and welfare implications of the effects of maternal deprivation, and suggest some topics for future research.
\end{abstract}

(C) 2007 Elsevier B.V. All rights reserved.

Keywords: Weaning age; Maternal deprivation; Stereotypic behaviours; Welfare; Perseveration

* Corresponding author. Tel.: +44 1865271214.

E-mail address: naomi.latham@zoo.ox.ac.uk (N.R. Latham). 


\section{Introduction}

Maternal deprivation is widespread among captive animals, particularly in the form of separation from the mother earlier than would happen naturally. All commercially reared animals are separated from their mothers/parents before the age at which they would naturally leave their natal territory or social group in free-living conditions. Some animals are even removed from their mothers while still dependent on milk, perhaps within hours of birth, and others are denied any parental contact at all. The point at which animals are separated from their mothers/parents in commercial systems is typically called 'weaning' and in this paper we use it in this way (although we acknowledge that the term actually refers to the biological process during which animals naturally stop suckling from their mother (see Martin, 1984)). Thus, we use the term 'early weaning' to refer to earlier than standard weaning practices in captive situations. In this paper, we review the impact of weaning and similar manipulations on abnormal behaviour.

\subsection{Widespread maternal deprivation}

Earlier than natural weaning from the mother is particularly evident in commercially reared animals, where fast reproductive turnover is important for profit. For example, dairy calves may be separated from their mothers at only a few hours old (e.g. EPA, 2004a), yet cattle do not naturally wean their calves until 9-11 months (Reinhardt and Reinhardt, 1981; Veissier et al., 1990; Reinhardt, 2002). Farmed piglets are separated at 2-6 weeks old, yet under (semi-)natural conditions they may suckle until 3-4 months old (Jensen, 1986; Jensen and Stangel, 1992; Stolba and Wood-Gush, 1989; Petersen, 1994). Farmed mink are separated from their mothers at around 7 weeks, despite still showing some suckling at this age and not dispersing for at least another month under free-living conditions (indeed young females may not leave their mother until 10 or 11 months old - see Jeppesen et al., 2000; European Commission Report, 2001). Furthermore, poultry eggs are sent to hatcheries for incubation (see EPA, 2004b), eliminating completely parental contact that would normally extend for 5-12 weeks (McBride et al. 1969, cited by Perré et al., 2002). Curtailed maternal care is also found in research, companion and zoo animals, although typically less early in development. Here, infants are usually removed once they have stopped suckling, even though their natural dispersal age would be much later. For example, laboratory mice are typically separated from their mothers at 21 days, yet free-living mice would not naturally disperse from their parental territory until approximately 35-42 days (see Latham and Mason, 2004). Similarly, elephant calves are separated from their mothers almost as soon as they are weaned off her milk (at roughly 3 years) (Clubb and Mason, 2002), yet young males would not naturally leave the mother and natal herd until 7-12 years later (Eisenberg et al., 1971; Douglas-Hamilton, 1972; Sukumar, 1989), and females would naturally remain with their mother and natal herd for life (Moss and Poole, 1983; Sukumar, 1989).

Captive animals may additionally experience maternal deprivation of a qualitative nature, e.g. via poor quality maternal care. Early separation from their own parents and/or subsequent housing in unnatural social groupings may mean that females are not properly exposed to young infants or the parental behaviour of more experienced females prior to the birth of their own offspring. In some species, such females may then be inexperienced with their own infants (e.g. chimpanzees, Goodall and Toms, 2003). Hand-reared animals similarly do not experience true maternal behaviours, despite the efforts of their human surrogate parents, and this may become apparent in their later behaviour (Kreger et al., 2004, 2005). Furthermore, captive females may be incapable of exhibiting some or all maternal behaviours. This may be due to the physical 
restraints of their environment - for example stall-housed sows cannot perform the sniffing and nose-to-nose behaviours exhibited by sows in unrestrained conditions (see Harris and Gonyou, 1998). Mothers may also not appropriately display maternal behaviours if the excessive performance of other behaviours, such as stereotypic behaviours, occupies much of their active time (e.g. Sørensen and Randrup, 1986). Finally, social species which display allo-parental care may, in captivity, be exposed to fewer 'aunts' (allomothers) or other helpers than would occur in nature (e.g. elephants, reviewed Clubb and Mason, 2002).

\subsection{Stereotypic behaviours}

Maternal deprivation is thus a common part of early experience for captive animals. Could it play a role in a common response to captive conditions: stereotypic behaviour? Stereotypic behaviour has been defined as 'repetitive, invariant and apparently functionless behaviour' (e.g. Ödberg, 1978; Mason, 1991b, 1991c). Behaviours traditionally categorised as stereotypic under this definition are widespread among captive animals: we have estimated (Mason and Latham, 2004) that such behaviours are performed by at least 85 million animals worldwide each year. However, one of us (GM) has suggested recently that this definition should be updated, placing more emphasis on biological causal factors, and less on aspects of phenotype that are poorly specified (e.g. 'invariant') or hard to measure (e.g. the presence or absence of proximate function). Mason (2006a) suggests instead that stereotypic behaviours are 'repetitive behaviours induced by frustration, repeated attempts to cope and/or CNS dysfunction'. Behaviours whose biological causal factors are unknown should instead be defined as abnormal repetitive behaviours (ARBs). Updating the definition in this way reflects more accurately how most people use the term in practice, and reflects why such behaviours are worthwhile topics for study (Mason, 2006a). This updated definition also allows us to be less concerned with benign examples of rhythmic behaviour, such as a dog chasing a ball or a cat kneading a pillow; and instead to include repetitive behaviours known to stem from some environmental deficit causing frustration or CNS dysfunction, such as belly-nosing in piglets and allo- and teat-sucking in calves, which have not previously been called stereotypic behaviours because of their rather variable and transient nature.

To answer the question of whether maternal deprivation plays a role in the development of stereotypic behaviour, we first review scenarios where maternal separation is part of a suite of changes that are imposed on an infant, particularly looking at studies of primates in the 1960's, reports of institutionalised children, studies of captive-born versus wild-caught individuals, and hand-rearing studies. In the next section we discuss factors that can influence the magnitude of these effects. Then in the following section we try to isolate the role of maternal deprivation per se, by reviewing the few cases where maternal loss or qualitative aspects of maternal care have specifically been investigated. We subsequently look at some of the mechanisms by which such early experiences can cause or enhance stereotypic behaviour. Finally, in the discussion we review the practical and welfare implications of such findings, and suggest topics for future research.

\section{Early experience that involves maternal deprivation, and the development of stereotypic behaviour}

\subsection{Evidence from primate studies involving maternal deprivation}

The first scientific accounts of the lasting effects of maternal deprivation in animals stemmed from the research of Harlow et al. several decades ago. Young primates naturally have a long 
period of dependency on their mothers, who have important roles beyond the mere provision of milk, e.g. transporting the infants, providing comfort. Thus it is perhaps unsurprising that being deprived of maternal care has major effects, including promoting stereotypic behaviour. Here, we summarise a recent thorough review by Novak et al. (2006); also reviewed by Sackett et al., 1999; Sanchez et al., 2001; Gilmer and McKinney, 2003).

Harlow's early studies (e.g. Harlow et al., 1969), which perhaps ironically stemmed from his desire to discover the nature of love (see Slater, 2004), documented the effects of maternal deprivation on rhesus macaques (Macaca mulatta). Harlow reared infants in environments with varying degrees of maternal and peer isolation. In the most severe treatments, infants were removed from their mothers shortly after birth and reared by humans in a nursery for the first month. They were then either fully or partially isolated. Fully isolated macaques were placed alone in small cages where they were unable to see, hear or physically interact with other macaques until they were 6 months old. Partially isolated macaques were able to see and hear other individuals but not interact with them for between 3 and 12 months. The macaques were then group-housed with like-reared individuals, although some remained isolated due to aggressiveness. Harlow compared these animals during infancy and at later stages of development with individuals reared with mothers and/ or peers. He found that compared to peer-reared macaques both groups of isolate-reared animals developed more whole body stereotypic behaviours, such as rocking and bouncing, and selfdirected stereotypic behaviours, such as self-clasping and digit-sucking. By 3 years of age the selfdirected stereotypic behaviours gave way to other kinds of stereotypic behaviours, such as somersaults, head bobs and in some cases self-injurious behaviour. These stereotypic behaviours occupied up to $35-60 \%$ of their active time. Stereotypic behaviour levels also remained elevated for a number of months after housing conditions were normalised, at least as far as they could be given these animals' social deficits. Other less extreme studies have since found similar long-term increases in stereotypic behaviours and self-directed behaviours in peer-reared rhesus macaques and chimpanzees, particularly in those individuals reared in incubators during the first few months of life (see Champoux et al., 1991; Spijkerman et al., 1994; Bloomsmith et al., 2002). Interestingly, primates confiscated from touring zoos and circuses, which possibly experience more early social and environmental deprivation than those reared in 'recognized' zoos, also exhbit higher levels of abnormal behaviour than those reared in 'recognized' zoos (Mallapur and Choudhury, 2003; Mallapur, 2005).

\subsection{Evidence from institutionalised children}

Harlow's studies included only a relatively small number of experimentally manipulated primates. However, similar effects have also been seen in human infants, and on a much larger scale. Henry Chapin pioneered studies into the effects of institutionalisation in young children over a century ago, revealing that $30-100 \%$ of infants admitted to asylums during their first year of life died prior to their second birthday (see Gray, 1989). Chapin then pioneered changes to the design of asylums and implemented fostering programmes, and by the mid-1940s death rates had reduced significantly (see Spitz, 1945). However, the survival of these infants revealed new problems with early institutionalisation - such infants later showing mental, social and behavioural deficits, including stereotyped motor behaviour (Spitz, 1945). These studies were to inspire the influential work by John Bowlby, and his theories on attachment and the effects of separation of children from their mothers (Bowlby, 1969, 1973, 1980).

During the 1980s in Romania, the problems of early institutionalisation were dramatically brought back into the public eye. Approximately 65,000 children were separated from their parents 
and placed in orphanages, $85 \%$ being placed within the first month of life (see Chugani et al., 2001). Similarly to the infants studied by Spitz 40 years earlier, these children lived in bare rooms, often spending $20 \mathrm{~h}$ a day confined to separate cribs, and having minimal contact with other children and adults (with only one care-giver for every 10 infants, or for every 20 children over the age of three) (see Chugani et al., 2001; Mason, 2006b). They were also exposed to physical and sensory deprivation (Fisher et al., 1997; Gunnar, 1999; Beckett et al., 2002); and nutritional deprivation too, children often being left alone with propped bottles containing semi-liquid feedings (Monsen, 2004; and 59\% were below the 5th percentile for weight when later adopted, Chugani et al., 2001). Thus, it is perhaps not surprising that children in these institutions displayed stereotypic behaviours, including rocking back and forth on hands and knees, or standing, holding their cribs' railings, shifting from foot to foot (Carlson and Earls, 1997; Fisher et al., 1997).

During the early 1990s, following the fall of Ceaucescu, thousands of these orphans were adopted internationally, with several hundred then being studied by developmental psychologists (e.g. Carlson and Earls, 1997; Fisher et al., 1997; O'Connor et al., 2000; Chugani et al., 2001; Rutter et al., 2004). These studies revealed that the orphans continued to exhibit behavioural, as well as cognitive and emotional, problems long after adoption. For example, half of the children still performed stereotypic behaviours, such as rocking and hand movements, a year postadoption; and a quarter performed self-injurious behaviours, such as head-banging and eyepoking (e.g. Fisher et al., 1997; Beckett et al., 2002; MacLean, 2003). Even at age six, stereotypic behaviours and self-injurious behaviour continued to be performed by 18 and $13 \%$ of the children respectively, and 15\% still had problems chewing and swallowing food (Monsen, 2004). Thus, the suite of deprivations these children experienced, including maternal loss, caused stereotypic behaviours that in many cases persisted even in normal environments.

\subsection{Comparisons of wild-caught and captive-born animals}

Wild-caught animals placed into captivity as sub-adults or adults, and thence having had a normal rearing experience with their mothers, show less stereotypic and abnormal behaviours than their captive-bred conspecifics in almost every reported instance (Mason, 2006c). Thus in laboratories, wild born chimpanzees (Pan troglodytes) are less stereotypic than laboratory-born animals (Davenport and Menzel, 1963). Stereotypic behaviours (and 'faeces-smearing') are absent altogether in wild-caught macaques (Macaca mulatta and Macaca silenus) in marked contrast to their zoo- and laboratory-born peers (Mason and Green, 1962; Berkson, 1968; Mallapur et al., 2005). Likewise, wild-caught black rats (Rattus rattus), bank voles (Clethrionomys glareolus) and African striped mice (Rhabdomys pumilio) typically show negligible stereotypic behaviour in laboratory cages, unless caught very young, although these behaviours emerge rapidly in most of their cage-born offspring (Sørensen and Randrup, 1986; Callard et al., 1999; Schoenecker et al., 2000; Jones and Pillay, 2006). Furthermore, in surveys, zoo-keepers also score zoo-born black rhinos (Diceros bicornis) as more stereotypic than wildcaught animals (K. Carlstead, Hawaii, personal communication 2004) - yet, interestingly, they are also scored as more friendly towards keepers (Carlstead et al., 1999). In carnivores the picture is less clear-cut, but wild-caught individuals still never seem more stereotypic than captive-borns. Pacing has been found in only a quarter of wild-caught beech martens (Martes foina), but in all of their offspring (Hansen, 1992 who also reports that abnormal fur-chewing was absent in wildcaught animals, but common in farm-born martens). Studies of polar bears (Ursus maritumus) and other ursids have detected no differences or non-significant differences stereotypic behaviours (Van Keulen-Kromhout, 1978; Ames, 2000), although a more recent study's 
preliminary analyses suggest that some wild-caught male polar bears pace less than zoo-born males (D. Shepherdson, Oregon, personal communication 2005).

There are four partial counter-examples. Caged wild-caught blue-jays spend more time routetracing than hand-reared birds - but they are less prone to stereotypic spot-pecking than captiveborn animals (Keiper, 1969). Wild-caught apes have shown more regurgitation and re-ingestion than captive-born conspecifics, but here the wild-caught animals were brought into captivity as very young infants and so were prematurely separated from their mothers (Gould and Bres, 1986). Wild-caught grey African parrots are also more prone to feather-picking in captivity than are captive-bred animals - but again, at least some of these birds would have experienced maternal deprivation, having been taken from their parents as nestlings (Schmid, 2004). Finally, wild-caught giraffes show a trend to exhibiting more pacing than captive-born individuals (Bashaw et al., 2001), but here the sample size was very small (under 6).

Thus overall, where wild-caught animals have had normal early socialisation periods, they typically seem protected from developing abnormal behaviour when placed in captivity. However, such wild-caught animals would also have matured in physical environments more complex and spacious than the typical captive enclosure, and we cannot assess the extent to which early physical versus maternal deprivation accounts for the greater stereotypic behaviour of captive-bred animals.

\subsection{The effects of human-rearing versus mother-rearing}

The hand-rearing of young captive animals by humans is sometimes necessary, for instance due to maternal rejection (Novak et al., 2006). Hand-rearing is generally a strategy of last resort because it can produce undesirable life-long changes in behaviour, such as heightened fear and aggression and poor social and parenting skills (e.g. Mellen, 1992; Ryan et al., 2002; Kreger et al., 2004). It has also been linked to the increased performance of stereotypic behaviours. For example, hand-reared chimpanzees and gorillas are consistently more stereotypic than their mother-reared conspecifics (Meder, 1989; Marriner and Drickamer, 1994; Nash et al., 1999). Even animals that are hand-reared but have contact with peers may go on to exhibit higher levels of stereotypic behaviour than mother-reared individuals (Martin, 2002; see also Atlanta Fulton County Zoo, 2005 for an anecdotal report of increased oral stereotypies in peer-reared giant pandas). Furthermore, recent survey data show that hand-reared parrots are more prone to feather-pecking (Schmid, 2004). There are two partial counter-examples to this. Firstly, Nash et al. (1999) found that mother-reared chimpanzees perform less stereotyped rocking and selfsucking; and secondly, Rybiski Tarou et al. found no apparent effects of hand-rearing on stereotypic behaviours in zoo-housed prosimians (possibly due to the small number of handreared animals included in the sample population) (Rybiski-Tarou et al., 2005). Interestingly, in addition to these examples, Wielebnowski et al. (2002) found that hand-reared clouded leopards (Neofelis nebulosa) show a trend to exhibiting lower corticosteroid levels than mother-reared individuals; and Barnes et al. (2002) reported that hand-reared duikers tend to be calmer and less stress-prone than mother-reared individuals. Thus, as in wild-caught animals, rearing conditions that increase stereotypic behaviour do not necessarily lead to poorer welfare in adulthood.

\section{Factors affecting the magnitude of early deprivation effects}

Although it is tempting to focus on maternal deprivation being the cause of resulting behavioural changes, the assumption being that the younger the infant the greater the impact of 
maternal loss is, effects may instead reflect age-specific effects of novelty, acute stress, etc. Thus, below we look at the factors that may influence these behavioural effects.

\subsection{Age at weaning}

A number of lines of evidence indicate that the earlier weaning occurs, the more abnormal behaviour young animals will go on to perform. Perhaps best-studied example here is belly-nosing in piglets (see also Widowski et al., 2008). Belly-nosing involves rooting or nudging at the flanks and undersides of fellow piglets (Weary et al., 1999; Worobec et al., 1999). Numerous studies have found that the earlier piglets are removed from their mothers, the more belly-nosing they perform (e.g. Bøe, 1993; Weary et al., 1999; Worobec et al., 1999). Similarly, studies in laboratory mice have found that mice weaned at 17 days perform more bar-biting than those weaned at the standard age of 20-21 days (Würbel and Stauffacher, 1997). Bar-biting is thought to stem from escape behaviour in order to return to the mother, perhaps as a result of a suckling motivation (Würbel and Stauffacher, 1997). These effects on stereotypic behaviour can take some time to emerge, and the same has been seen in farmed mink. Here, earlier age of separation (e.g. 7-8 weeks versus 9-10 weeks) has also been linked to a later, delayed increase in stereotypic behaviours, such as pacing, and tail-biting (in which fur is sucked or bitten off the tail), as well as resulting in stereotypic behaviour that was more predictable in appearance (Mason, 1995; Jeppesen et al., 2000). Interestingly, studies in mink have also shown that the earlier females are separated from their mother, the more likely it is that they will develop stereotypic behaviour patterns that involve their nest-box (Mason, 1991a). Furthermore, there have long been anecdotal reports that kittens removed early from their mothers will be more likely to develop 'wool-sucking' than later-separated animals (see Morris, 1987; Moon-Fanelli, 2005; see also Bradshaw et al., 1997). There are, similarly, anecdotal reports that age at separation influences the development of cribbing behaviour in horses (King, 2005), although formal studies have failed to find such effects (Waters et al., 2002). There is also a report of early separation from the mother causing stereotypic behaviour in a zoo-housed dolphin (Laule, 1993). Finally, age at separation can affect other abnormal behaviours. Thus, Novak et al. (2006) note that socially reared monkeys that develop self-injurious biting when isolated are those separated from their mothers at less than 2 years old.

\subsection{Developmental stage at weaning}

Young animals develop at different rates and so may be at different developmental stages at a particular weaning age. For example, ICR CD-1 mice can weigh between 8 and $16 \mathrm{~g}$ at standard weaning age (21 days, N. Latham, unpublished data), and the ears of particularly small individuals sometimes have not fully extended away from the side of their head at this age (N. Latham, personal observation) - a developmental process that normally occurs in mice between 18 and 20 days of age (Berry, 1970). So, does developmental stage at weaning influence later stereotypic behaviour?

Würbel and Stauffacher (1997) found that lighter mice at weaning performed more rearing and jumping than heavier littermates, and also found a negative correlation between weight at weaning and bar-biting (similar results have also been found by Latham, 2004). This may be due to increased escape attempts, due to the life-long disadvantages of lighter weaning weight under natural conditions (Würbel and Stauffacher, 1997; Latham and 
Mason, 2004). However, in contrast, Nevison et al. (1999) found that heavier mice at weaning performed more bar-biting at the side of their cages. Weight at weaning may also influence the form or location of mouse stereotypic behaviours. For example, weight at weaning is associated with the prevalence of rearing or climbing in the build-up to stereotypic bar-biting (Würbel and Stauffacher, 1997, 1998) and the level of bar-biting exhibited at either the top or side of the cage (e.g. Nevison et al., 1999) at roughly 80 days of age.

\subsection{Whether weaning is gradual or abrupt}

Natural weaning processes (the cessation of suckling) and subsequent dispersal from the mother under free-living conditions are typically gradual, but commercial weaning practices are very abrupt and this may influence the development of stereotypic behaviours (e.g. Jeppesen et al., 2000; Waters et al., 2002). Few studies have looked at this formally, however some studies in horses and beef cattle report gradually weaned foals and calves to be 'less stressed' and to vocalise less respectively (e.g. Apter and Householder, 1996; Haley et al., 2005). However, Moons et al. (2005) found that brief periods of separation prior to weaning, which were intended to reinforce the mare-foal bond and facilitate the way foals cope with later stressors, did not produce any evidence of reduced physiological or behavioural stress-responses at weaning.

\subsection{Nature of the pre- and post-weaning environment: enrichment and diet}

The post-weaning environment has a major influence on the development of stereotypic behaviours. For example, mink housed in small cages following weaning develop more stereotypic behaviours than those housed in larger cages (Jeppesen et al., 2000). Likewise, piglets housed in small flat-decks post-weaning develop more pen-mate-directed rooting, chewing and tail-biting than those housed in larger pens (Bøe, 1993). Similarly, foals singly housed in stalls ('box-weaned') or peer-grouped in barns following weaning develop more pawing and licking behaviours than group-housed foals in paddocks (e.g. Heleski et al., 2002; Nicol et al., 2005). Indeed, foals that are box-weaned are more than twice as likely to develop behavioural problems, such as wood-chewing (Waters et al., 2002). Since the development of equine oral stereotypic behaviours, such as cribbiting, are linked to gastric inflammation and ulceration, such behaviours in foals may in part potentially be linked to the feeding of concentrated diets following weaning (Waters et al., 2002; Davidson, 2005). Interestingly, in dairy calves, stereotypic sucking behaviour following weaning can be reduced by slowing milk delivery during feeds and allowing suckling through a teat (Hammell et al., 1988; de Passille, 2001; Loberg and Lidfors, 2001), and allowing brief suckling from a cow post-milking (Margerison et al., 2003; see also review by Jensen, 2003).

In other instances, both pre- and post-weaning environments are manipulated and their impacts assessed. Thus piglets housed in outdoor enclosures both pre- and post-weaning exhibit less belly-nosing after weaning than piglets housed in indoor confined conditions (Hotzel et al., 2004). Similarly, young mice reared pre- and post-weaning in enriched cages develop less stereotypic behaviour than those reared in barren cages (Latham, 2004). Interestingly, Latham (2004) failed to find an effect of weaning age on later stereotypic behaviour (in contrast to the results of Würbel and Stauffacher, 1997), perhaps because her subjects were isolation-housed after weaning, itself a very abnormal scenario (see also Schoenecker et al., 2000 for similar findings in bank voles). Finally, there is some intriguing evidence that the post-natal environment may interact with weaning age to affect the impact of maternal separation. Thus, O'Connell et al. 
(2005) report that the effects of weaning age ( 3 or 5 weeks) on belly-nosing are only apparent when piglets are reared in barren environments between birth and weaning, but not when reared in enriched environments during this time.

\subsection{Length of deprivation period or its correlates}

In the Romanian orphans discussed earlier, the persistence of rocking and self-injurious behaviour was most marked the longer the child had been institutionalised, and the less time s/he had had with the new family (Fisher et al., 1997; Beckett et al., 2002). However, all such findings came from age-matched cross-sectional studies, and thus length of time in the institution was intimately positively correlated with age at adoption, and negatively correlated with amount of time with the new family. Unfortunately, therefore, one cannot disentangle from these papers alone the relative roles of the ages at which the children were deprived versus the lengths of their periods of deprivation and/or of exposure to normal homes: the results are merely consistent with a greater impact of early or prolonged loss, but nothing stronger than that can be inferred.

\subsection{Summary}

Overall, there is thus a substantial and wide-ranging body of evidence that conditions where the mother is not present early in life appear to increase the development of stereotypic behaviours. There is similarly evidence that a variety of factors may influence the severity of that maternal deprivation and hence its effects on the development of stereotypic behaviours. However, the examples discussed in the previous two sections typically involve the removal of the infants from the mother, rather than vice versa, and expose the infants to a whole suite of other changes, such as decreased environmental size and complexity, exposure to a human surrogate, social deprivation and sometimes nutritional deprivation. So, what is the role of maternal loss per se?

\section{The role of maternal deprivation per se}

Despite the vast array of literature about the effect of 'maternal deprivation', very few experiments have actually addressed the question of the effects of the loss of the mother per se. Perhaps the closest study to this is that of brooded and non-brooded domestic fowl (Gallus gallus domesticus) by Perré et al. (2002). Perré et al. reared half of the chicks in small groups with broody hens (not their mothers) until the hens became indifferent to the chicks, at approximately 8 weeks, and were removed. The remaining chicks were group-reared without hens, and these groups were given heat lamps that were removed at the same stage as the hens from the brooded chicks. Observations of the pullets when they were 3-7 months old revealed that 3.5 times as many pullets that had not been brooded as chicks performed feather-pecking and spent more time in the behaviour than pullets that had been brooded as chicks.

Evidence of the role of maternal loss by itself also comes from reports by Spitz (1946) of the behaviour of institutionalised infants, normally cared for by their mothers, when their mothers were separated from them for several months. Following separation, previously happy infants became increasingly weepy and performed noticeably more finger-sucking, and some also played with their faeces. These behaviours continued and worsened until the mother was returned, at which point the behaviours ceased and the infants reportedly returned to their previously contented state. Similar depression-like and repetitive behaviours have been reported in infant bonnet monkeys (Macaca radiata) when their mothers are separated from them. 
Interestingly, these effects are alleviated if the infants have strong social connections with other individuals in their group (Reite et al., 1989).

Studies in deer and cattle also allude to the importance of maternal loss per se. Haigh et al. (1997) compared wapiti (Cervus elephas) calves that were moved during weaning to either a paddock adjacent to one housing their dams or one which was some distance away and visually obscured from the paddock housing their dams. They found that the calves housed adjacent to their dams following weaning again performed less fence-line pacing than those housed at a distance. In this study, calves in pastures adjacent to their dams were able to stand within a few metres of their dam following weaning, and unfortunately the authors do not report the behaviour of the calves if or when the dams were later moved to a distant enclosure. However, in a similar study, Price et al. (2003) note that fence-line contact between calves and dams decreases over the 5 days following weaning, possibly as the calves and dams gradually become more independent of each other.

In addition, there are some studies in which the qualitative aspects of maternal care were investigated or at least implicated. There is, for example, some evidence that human children in residential care with a suspected history of prior child abuse display more frequent stereotypic behaviours than 'non-abused' children (Troster, 1994). In a study of 225 Thoroughbred and partThoroughbred horses, foals of dominant mares were found to go on to develop more behavioural problems than foals of middle- or low-ranking mares. This may have been be due to the influence of the mare behaviour towards the foal prior to weaning, and the nature of the mare-foal bond and effects of weaning (Waters et al., 2002; Nicol and Badnell-Waters, 2005). In addition, the proportion of stereotypic behaviours in mink (from multiparous females) that resemble nipplesearching movements is predicted by their weight at weaning. This may reflect frustration caused by milk restriction by the female imposes when the kits reach a certain weight (Mason, 1991a). Furthermore, mother-reared chimpanzees perform more coprophagy and self-depilation than hand-reared animals, possibly because these behaviours have been learned from the mother (Nash et al., 1999). Finally, a study by Olsson et al. (1990) found that sows whose mothers were tethered during farrowing and lactation performed more biting when they themselves were later tethered than sows from non-tethered mothers.

These papers thus suggest, albeit it in very different ways and via very different mechanisms, a role of maternal contact per se, all other variables held constant, on later vulnerability to stereotypic behaviour. But whether it is the loss of the mother, or the suite of changes associated with weaning, what are the mechanisms that cause early deprivation to lead to stereotypic behaviour?

\section{How early deprivation leads to stereotypic behaviour}

Stereotypic behaviours generally appear in normal individuals housed in unnatural, restrictive environments that cause them to perform the same behaviour time and time again. The repeated behaviour may be one that the animal is motivated to perform or it may substitute for a highly motivated behaviour, and over time the behaviour may become performed out of habit (see Mason and Latham, 2004; Mason, 2006a). In some cases, however, restrictive, unnatural environments can lead to life-long changes in CNS functioning and behavioural control processes, creating abnormal individuals unable of preventing themselves from repeating behaviours, even when the behaviour or its repetition are inappropriate (Cabib, 2006; Garner, 2006; Lewis et al., 2006). Thus, in many instances, weaning promotes the rapid emergence of stereotypic behaviours whose 'source behaviours' (see Ödberg, 1978; Mason, 1991b, 1991c; Clubb et al., 2006) may include natural mother/offspring behaviours, escape or exploration, and the early expression of normal adult 
behaviours. However, weaning may additionally, or alternatively, lead to lasting changes in motor control, and also motivational state and temperament, that may influence later stereotypic behaviour. These could lead to delayed effects not evident until some time after weaning.

\subsection{Frustrated motivations to suckle, or to receive other forms of maternal contact}

A number of stereotypic behaviours appear to be frustrated suckling or related to particular aspects of mother-offspring behaviour. Thus the fact that the motor patterns involved in belly-nosing appear very similar to the massaging movements that piglets direct towards the sow's udder when suckling (described by Gill and Thomson, 1956) would seem to suggest that belly-nosing stems from suckling attempts. Indeed this is the most common explanation of this behaviour (e.g. Weary et al., 1999; European Commission Report, 2001; Hotzel et al., 2004). The non-nutritive sucking of dairy calves is also thought to result from the motivation to suckle the mother's teats - a behaviour which may assist digestive processes by stimulating the release of insulin and cholecystokinin (de Passille, 2001; see also Veissier et al., 2002). Similarly, the woolsucking behaviour exhibited by domestic cats, particularly Siamese breeds, is thought to stem from the motivation to suckle (Morris, 1987; Mackie, 2001).

The stereotypic behaviours of deprivation reared primates seem to stem from other aspects of mother-infant interactions. Thus, self-clasping in young macaques in maternal deprivation studies (see earlier) can be reduced by giving them a warm, terrycloth-covered 'surrogate mother' to clasp to instead; and adding a rocking motion to the surrogate mother reduces stereotypic rocking in the infants (reviewed Novak et al., 2006). Interestingly, species differences in the role of clinging during mother-infant interactions have been suggested to underlie why self-clasping almost always accompanies rocking in monkeys but seems to be 'optional' in humans (Berkson, 1967).

\subsection{Frustrated motivations to escape}

Other stereotypic behaviours induced by weaning appear to be linked to escape behaviour, either due to motivation to get out of an unpleasant environment or to approach a desired stimulus or environment. Most evidence of this is found in studies of laboratory rodent behaviour. Barbiting and back-flips can develop rapidly in young mice (Mus musculus), gerbils (Meriones unguiculatus), bank voles (Clethrionomys glareolus) and black rats (Rattus rattus) when moved from the natal cage (Callard et al., 1999; Garner, 1999; Waiblinger and Konig, 2004; Würbel, 2006c). In mice, at least, these seem to begin as escape attempts and appear to stem from two different strategies. Mice either rear up at the cage wall and attempt to climb or jump over it leading to stereotypic jumping; or climb up the food rack and attempt to squeeze or gnaw their way through the bars - leading to bar-biting (Würbel et al., 1996; M. Jones, personal communication 2006).

The influence of escape motivation in bar-biting in laboratory mice has been most elegantly demonstrated by Nevison et al. (Nevison et al., 1999; Lewis et al., 2001), who found that mice preferentially chew at bars in sections of the cage lid that are opened periodically (thereby being those most likely to offer the opportunity to get out of the cage). Examples of escape-related stereotypic behaviours in non-rodent species include the intense albeit transient pacing of young pygmy hippopotamuses (Chereopsis liberiensis) after removal from their mother (Stroman and Slaughter, 1972); transient pacing in briefly maternally separated normally reared rhesus monkey infants before these animals lapse into something like 'despair' (reviewed Novak et al., 2006); 
and jumping in early weaned piglets, earlier weaning leading to greater amounts of jumping (Worobec et al., 1999).

\subsection{Frustrated motivations to perform normal adult behaviours}

In some cases, weaning simply exposes animals to the circumstances and cues that cause stereotypic behaviours to develop, and the effects are the same regardless of age. For example, in Thoroughbred horses age at weaning, in contrast to environment following weaning (see earlier), does not influence the type or amount of stereotypic behaviours foals develop. Foals merely develop them sooner, with crib-biting and wood-chewing appearing in the first few weeks after being moved to an adult diet and stabling regime, regardless of the age at which this occurs (Waters et al., 2002). Similarly, some suggest that belly-nosing may, rather than reflecting suckling motivation, instead develop as a result of the increased motivation to root during the enforced move to nutritional independence (Torrey and Widowski, 2004; Widowski et al., 2008). Here again it is not specifically the loss of the mother that elicits behaviours that lead to stereotypic behaviours, but the suboptimal nature of the post-weaning environment at whatever age the animals are exposed to it.

\subsection{Delayed and/or lasting effects on behaviour: pervasive changes in temperament, motivational state or motor control?}

From the examples above, there seems to be evidence that weaning can trigger rapid-onset stereotypic behaviours in young animals stemming from some source of immediate frustration. However, some such stereotypic behaviours can persist long after frustration should have waned. Thus, for example, mouse stereotypic behaviours do not decline once natural dispersal age passes, but instead persist or even increase (e.g. Latham, 2004). More anecdotally, the same seems true for oral stereotypic behaviours in a subset of early separated cats, pigs and cattle (Fry et al., 1981; Morris, 1987; T. Widowski, Guelph, personal communication 2005). Furthermore, in deprivation reared macaques, the initial stereotypic behaviours that appeared to be related to thwarted mother-infant interactions, such as digit-sucking and self-clasping, decline over time and are replaced by the increased performance of stereotypic behaviours, such as headbobbing and somersaults, which appear less specific to the loss of the mother (Novak et al., 2006). Some stereotypic behaviours may persist even if conditions are improved or normalised, e.g. in laboratory rodents and adopted orphans (Cooper et al., 1996; Fisher et al., 1997; Beckett et al., 2002).

Indeed, the effects of maternal deprivation can sometimes remain hidden until young adulthood. Thus, mink weaned at 7 weeks are no more active over the following 2 months than those weaned at 11 weeks (a more natural dispersal age). However, when pacing and similar behaviours appear 3-4 months later, the early weaned animals exhibit stereotypic behaviours that are both more frequent and less variable than their conspecifics that were separated from their mother at a more natural age (Mason, 1992; Mason et al., 1995; Mason, 1996; Jeppesen et al., 2000). Likewise, poultry chicks reared with hens show no less feather pecking at 2 months than chicks reared with peers alone (Roden and Wechsler, 1998), but show less of this behaviour once they are 3-7 month old pullets (Perré et al., 2002). So, how might weaning cause these delayed effects? Several possible mechanisms may be involved, either singly or in combination, and it is currently unknown to what extent these mechanisms may be adaptive or pathological. 


\subsubsection{Changes in social behaviour and preferences}

Maternal deprivation can lead to a host of behavioural changes that may subsequently affect how pleasant or aversive individuals find their environment and their behavioural responses to stressors. Thus, numerous primate studies indicate that maternal deprivation leads to abnormalities in almost every type of social interaction, including grooming, aggression and avoidance, mating and communication (Maestripieri and Carroll, 1998; Novak et al., 2006). Furthermore, nursery-peer-reared chimpanzees are less likely to engage in reproductive behaviour than normally reared individuals (King and Mellen, 1994), and peer-reared macaques show decreased parental competence as adults (Shapiro et al., 1994). Such findings are not limited to primates. Earlier age of weaning from the mother can lead to increased aggression and poorer social interaction in pigs (Fraser, 1978); and increased aggression and poor maternal behaviour in mice (e.g. Kikusui et al., 2005). Hand-reared birds can also display excessive aggression to conspecifics and be unable to perform normal courtship behaviours, in some cases even killing their mates (see Hawkins, 2001). Interestingly, some of these effects seem to be comediated by environmental conditions. Thus animals reared in more 'enriched' conditions show lower levels of aggression, less anti-social behaviour and better maternal care of their own offspring; and some suggest that this may indicate that animals reared in more 'enriched' environments are better able to cope following weaning (Hotzel et al., 2004; see also O'Connell et al., 2005; Tuyttens, 2005). So, maternal deprivation and its correlates may enhance subsequent stereotypic behaviour indirectly by rendering animals less able to cope in a low-stress manner with normal social interactions with conspecifics.

\subsubsection{Changes in anxiety and stress-responsiveness}

Heightened fearfulness is another behavioural characteristic of maternally deprived animals, and one that could potentially increase stereotypic behaviour, for example by increasing escape motivation in aversive situations. Novak et al. (2006), for example, note that peer-reared primates display greater fear responses to events, such as a caretaker walking into the room, that they exhibit more severe reactions to social weaning, and that they are more likely to consume alcohol. Isolate-reared primates in zoos may also display increased fearfulness, which can make the addition of environmental enrichments particularly problematic (Di Giovanni and Valente, 1999). Furthermore, the loss of a parent during childhood in humans significantly increases the likelihood of developing major depression during adulthood (Brown and Harris, 1978; Agid et al., 1999). Several studies of laboratory rats and mice also indicate that early separated animals exhibit higher levels of fearfulness than normally separated individuals, shown by reduced entries into the open arms of an elevated plus maze (Kikusui et al., 2004; Kanari et al., 2005; Kikusui et al., 2005) and reduced spontaneous novelty seeking (Adriani and Laviola, 2002).

The reported effects of maternal deprivation on later HPA (hypothalamic-pituitary-adrenal) axis activity are inconsistent (reviewed Gilmer and McKinney, 2003; Pryce et al., 2005; Novak et al., 2006). However, HPA axis activity does consistently increase following weaning in rodents and primates, sometimes for a number of weeks (e.g. Würbel and Stauffacher, 1997; Levine, 2000), although the presence of familiar conspecifics at weaning can reduce this response (Levine, 2000). Indeed, increased HPA axis activity following weaning in mice can predict later stereotypic behaviour (Würbel and Stauffacher, 1997). Interestingly, though, the effects of transient periods of maternal separation early in life on later HPA activity depend upon the duration of separation. Thus, brief periods of maternal deprivation prior to weaning can reduce stress-responsivity later in life (perhaps being an adaptive response to changes in maternal care that would naturally occur, e.g. as the mother goes out to forage), while prolonged separation can enhance HPA responses to 
adulthood stress (Kuhn and Schanberg, 1998). If early maternal deprivation causes a sustained increase in fearfulness or stress-responsivity, this would potentially alter behavioural responses to stressors later in life, increasing the likelihood of stereotypic behaviours in aversive conditions.

\subsubsection{Pervasive changes in perseverative tendencies and other aspects of CNS/behavioural functioning}

Maternally deprived and isolated primates exhibit long-term behavioural changes suggestive of altered behavioural functioning including perseverative behaviour, perseveration being 'the continuation or recurrence of an ... activity without the appropriate stimulus' (Sandson and Albert, 1984).

Thus, while isolates perform as well as control individuals in a standard learning test battery (Harlow et al., 1969), they are impaired during an extinction task, continuing to respond to a previously rewarded stimulus despite hundreds of unrewarded responses (Gluck and Sackett, 1976). Several studies have also found that maternal deprivation disrupts prepulse inhibition (the inhibition of the startle reflex following a weak preceding stimulus) in rats, indicating altered processing of sensory information akin to that seen in schizophrenia (Ellenbroek and Cools, 2002; Ellenbroek and Riva, 2003), although Finamore and Port (2000) found no such effects.

Likewise, although adopted Romanian orphans showed incredible improvements in health, behaviour and cognition following adoption (Fisher et al., 1997; Beckett et al., 2002; MacLean, 2003; Monsen, 2004), they often also had profound long-term deficits including general cognitive impairments, 'executive problems' like impulsivity, and autistic-like symptoms including circumscribed interests along with their lasting stereotypic behaviours (e.g. Chugani et al., 2001). Further suggestive of lasting CNS dysfunction was that persistent stereotypers had lower IQs than other adoptees, even when length of time in the orphanage was controlled for, typically (but not always) along with other 'quasi-autistic' symptoms (Beckett et al., 2002).

\subsubsection{Changes in neurotransmitter activity}

A number of invasive and/or post-mortem studies reveal lasting effects of early separation from the mother on CNS physiology. Note that these effects represent a different level of explanation, rather than an alternative, to the hypotheses given in Sections 5.4.1- 5.4.3.

Thus, in species as diverse as mice, pigs and poultry, maternal deprivation can affect dopaminergic (DA) and serotonergic activity (reviewed, e.g. Gilmer and McKinney, 2003; Novak et al., 2006), and some of the effects have been directly linked to the performance of stereotypic behaviours. For example, early, particularly neonatal, isolation can enhance DA release and turnover in various brain regions (Kehoe et al., 1996; McCormick et al., 2002; Matthews and Robbins, 2003), although it does not necessarily increase baseline DA levels (McCormick et al., 2002; Kosten et al., 2003). Fewer studies have examined the specific effects of weaning age, however some have found evidence suggestive of altered DA functioning or gross abnormalities of behavioural control. Thus, early weaned animals can be more sensitive to psychostimulant drugs and show enhanced psychostimulant-induced place-conditioning (Laviola and Dell'Omo, 1997; Adriani and Laviola, 2002). Furthermore, repetitive oral behaviours in very early weaned piglets are associated with decreases in the major metabolites of DA, and increased numbers of DA receptors in specific areas of the basal ganglia (Fry et al., 1981; Sharman et al., 1982; Mann and Sharman, 1983; see also Poletto et al., 2006 for a recent finding of changes in the expression of hippocampal genes involved in glucocorticoid regulation in very early separated piglets). Studies of the serotonergic system have revealed a number of effects of maternal deprivation - however the effects appear to be very complex. Thus, Kosten 
et al. (2004) report reduced serotonin activity in the ventral striatum; Vazquez et al. (2000) report up-regulation of serotonin receptors in the hippocampus and parietal cortex; Spear and Scalzo (1985) report increased serotonergic activity following maternal deprivation, although with lessening effect as rats reach laboratory weaning age (21-24 days); and Hall (1998) reported elevated serotonin turnover (for other reported effects, see also Sumner et al., 2002; Poeggel et al., 2003; Novak et al., 2006).

Given that dopamine and serotonin are involved in the neural reward pathways and emotional cognitive processes (e.g. Berridge and Robinson, 1998; Poeggel et al., 2003; Toates, 2004), it is perhaps not surprising that alterations caused by maternal deprivation may lead to some of the socio-emotional problems seen in maternally deprived individuals. Furthermore, given the role of dopamine and serotonin in behavioural control processes (Berridge and Robinson, 1998; Toates, 2004), it is also not surprising that alterations to these systems may lead to some of the persistent behavioural changes seen in maternally deprived animals (e.g. Jones et al., 1991, 1992).

\section{Discussion}

Typical husbandry practices expose most captive animals to maternal deprivation, through earlier-than-natural separation from the mother and/or inadequate maternal care. There is plenty of evidence that maternal deprivation can cause stereotypic behaviour in captive animals and children in poorly run institutions. Thus, earlier-than-natural separation from the mother can cause the immediate emergence of stereotypic behaviours, including belly-nosing in piglets, and/ or the emergence of stereotypic behaviours several months later, such as pacing in mink and feather-pecking in chickens. Some of these behaviours are fairly transient, e.g. belly-nosing, while others persist into adulthood, such as bar-biting in laboratory rodents.

Maternal deprivation may elicit stereotypic behaviours in young animals due to frustrated motivations to suckle or have physical contact with the mother, but may also alter animals so that they become more prone to developing stereotypic behaviours long after separation. Thus maternal deprivation may produce changes in temperament or stress-responsiveness that influence life-long behavioural responses to stressors, or may cause neural changes that make animals more prone to 'inappropriate' repetitive behaviour.

These processes are not mutually exclusive and may help to explain different stereotypic behaviours during an animal's life. For example, bar-biting in rodents and belly-nosing in piglets are thought to stem from frustrated suckling motivation, but rodent bar-biting continues and increases during adulthood, and there are anecdotal reports of belly-nosing persisting in adult pigs (see Bergeron et al., 2006; Widowski et al., 2008). Research also shows that the effects of maternal deprivation on stereotypic behaviour development are quantitative not qualitative. Thus, effects are graded depending upon the severity of the weaning process rather than being an all-or-nothing effect.

It is clear that the suite of changes that occur during weaning influence later stereotypic behaviour, but the role of maternal loss per se is currently less clear. However, a few reports from institutionalised children and brooded versus non-brooded chicks demonstrate that maternal loss by itself does indeed increase the prevalence and severity of stereotypic and other abnormal behaviours. Studies of children and horses also demonstrate that the nature of the relationship between mother and offspring (i.e. the quality of maternal care) may influence performance of stereotypic behaviours following weaning or later separation.

Whatever it is about typical weaning practices that leads to stereotypic behaviours, this is a problem that affects a phenomenal number of animals. Each year, Europe and the United States 
rear almost 16 billion farm, zoo and research animals (European Commission, 2005; Llorens Abando and Martinez Palou, 2006; Nuffield Council on Bioethics, 2005; U.S. Department of Agriculture National Agricultural Statistics Service, 2005a,b,c). There are few published figures that allow us to estimate the prevalence of stereotypic behaviours caused or exacerbated by earlier-than-natural separation from the mother. However, belly-nosing is reportedly performed by $11 \%$ and $6 \%$ of piglets weaned at 15 and 21 days respectively (Straw and Bartlett, 2001; Main et al., 2005). Thus, of the 250 million pigs reared each year (weaned at 2-4 weeks in the U.S., and at 4 weeks in Europe), approximately 13 million may perform belly-nosing. Furthermore, if maternal deprivation is implicated in feather-pecking in chickens, as suggested by the work by Perré et al. (2002), this would have massive effects. A survey of commercial layer hens in noncage systems found that feather-pecking was reported in $56 \%$ of flocks, with a mean of $30 \%$ of animals being feather-pecked in affected flocks (Pötzsch et al., 2001). Thus feather pecking could affect hundreds of millions of laying hens, either by being feather-peckers or being featherpecked by others.

\subsection{Implications of maternal deprivation for welfare and normalcy}

The emergence and repetition of behaviours stemming from escape behaviour to return to the mother or re-directed nursing behaviour suggest that the loss of the mother and the inability to suckle are perceived as aversive, and that the post-weaning environment is suboptimal. However, the consequences of performing stereotypic behaviours may differ depending upon whether stereotypic behaviours reflect frustration, or if they are 'DIY enrichments' that enable animals to cope with suboptimal environments (cf. Mason and Latham, 2004). The suggestion that the loss of the mother/inability to suckle are aversive is corroborated by increases in vocalisations (particularly high-frequency calls) thought to indicate distress following weaning in many farmed animals (Weary et al., 1999; Flower and Weary, 2001; Price et al., 2003; Orihuela et al., 2004). Indeed, piglets weaned at 2 weeks produce more high-frequency vocalisations and subsequently exhibit more belly-nosing than piglets weaned at 4 weeks (Weary et al., 1999; see also Würbel and Stauffacher, 1997; Würbel, 2006c). Thus if early separation from the mother and the inability to suckle are aversive and frustrating, it seems likely that the levels of such stereotypic behaviours will reliably reflect compromised welfare during the period following weaning.

Maternal deprivation may also have longer lasting influences on welfare by causing life-long changes in behaviour (reviewed by Sanchez et al., 2001) and stress-responsiveness. Thus, the increased aggressiveness, anxiety and social abnormalities exhibited by maternally deprived animals may well influence how pleasant or otherwise individuals find their environment, and hence their likelihood of developing stereotypic behaviours. Additionally, if early maternal loss renders animals less able to cope with aversive situations, we might predict that the earlier animals are weaned the greater the likelihood is of them developing stereotypic behaviours if they find their environment aversive later on.

Maternal deprivation may also alter the normalcy of captive animals. Such changes may be maladaptive (e.g. adaptive in an evolutionarily normal context but not in captivity), or reflect true dysfunction (cf. Würbel, 2006b). Thus, the finding that social status in mares can influence stereotypic behaviour in their foals shows how normal processes or traits can be risk factors under artificial conditions. Likewise, separation from the mother may influence brain functioning and behaviour in ways that are adaptive in free-living environments but maladaptive in captivity. For example, in free-living mice, long periods of maternal separation and earlier dispersal may occur when resources are low (reviewed Latham and Mason, 2004). Here a competitive, aggressive 
strategy may be more advantageous (see Sih et al., 2004). However, aggressiveness, and associated behaviours, such as routine formation (Benus et al., 1987, 1988, 1990; see also Gammie et al., 2003), induced by earlier-than-natural weaning are not appropriate or desirable in captivity (see Würbel, 2001). Similarly, early weaning-induced stereotypic and perseverative behaviour may be inappropriate in research animals (e.g. Latham, 2004). Some captive animals, however, such as Harlow's primates, experience maternal deprivation far beyond that that would ever happen in nature. Here, individuals exhibit changes in brain functioning and cognitive deficits that are extremely hard to reverse, and that reflect nothing but malfunction (see Mason, 2006a).

Although we have focussed on how quantitative and qualitative maternal deprivation in captivity may reduce welfare and increase stereotypic behaviour, there is also some evidence suggesting that being born in captivity and hand-reared may reduce fearfulness of humans. While such animals may be more prone to stereotypic behaviours, their overall welfare may be improved if their environments will entail life-long close contact with humans (e.g. zoo animals).

\subsection{Future research}

There is independent evidence that many of the stereotypic behaviours discussed here stem from underlying frustration, repeated attempts to cope or CNS changes. However, in some cases the role of such underlying causes has been inferred rather than measured, and the label of stereotypic behaviour may need confirming. Knowing whether repetitive behaviours stem from frustration or CNS dysfunction, or indeed both, is important because it tells us about the welfare and normalcy of animals, and potentially provides ideas for improving captive environments. Research does not necessarily need to identify the specific factor underlying repetitive behaviours (although some studies have done so, e.g. Wiedenmayer, 1997), simply that there is independent evidence that the causal situation is causing frustration or CNS dysfunction. Further research is also important where stereotypic behaviours stem from CNS dysfunction caused by early separation from the mother. Those studies that have identified a specific link between weaning age and neural dysfunction (Fry et al., 1981; Sharman et al., 1982; Mann and Sharman, 1983) have looked at animals weaned much earlier than would typically occur in commercial environments. Thus, it is currently uncertain whether typical weaning practices expose animals to a similar risk of CNS dysfunction. Furthermore, we have discussed how weaning typically involves a suite of changes, not just the loss of the mother. Thus, it would be useful to research the impact of maternal loss per se, particularly in species with differing maternal strategies. So, for example, assessing the effects of removing the mother while all other factors remain the same; and assessing whether these effects differ in species where neonates are naturally left for long periods while the dam forages (e.g. tree shrews) compared to species where infants suckle almost continuously for the first few days and then gradually experience longer periods of maternal absence (e.g. rats) (e.g. Manning and Dawkins, 1992; Kuhn and Schanberg, 1998). The impact of other changes that typically occur during weaning could similarly be assessed, including changes in peer groups (e.g. weaning with siblings or mixing litters), diet and the physical environment. The effects of qualitative aspects of maternal care on offspring behaviour are also an important area for further research, for example, the effects of: being reared by a mother that is physically unable to perform maternal behaviours; having a mother that is inexperienced, having been unable to learn maternal behaviour from experienced females; of being reared by a mother alone when young would naturally be reared by both parents (e.g. striped mice (Rhabdomus pumilio), Schradin and Pillay, 2003), or by a group of 'carers' (e.g. elephants, Clubb and Mason, 2002); and whether natural, adaptive differences in maternal strategy prove maladaptive in captivity (Würbel, 2006a). Finally, there are a variety of other factors that deserve 
further attention, such as developmental stage at weaning and the effects of sex differences in natural dispersal strategies, for example, where females remain with their natal group while males disperse to find new territories.

\section{Conclusion}

Almost all captive animals experience some level of maternal deprivation, from the extreme primate experiments of Harlow, through earlier than natural separation from the mother in many commercially reared animals, to qualitative differences in maternal care due to environmental restrictions or inexperience. Such poor or limited mothering can produce physiological and behavioural changes that are inappropriate and undesirable in captive animals, and which indicate poor welfare and abnormal functioning. Further research is required to identify how these effects can be minimised, and thus improve the welfare and normalcy of captive animals.

\section{Acknowledgements}

We would like to thank Robert and Joan Hinde for inspiring and informing GJM's early interest in social experience. We also thank Tina Widowski and colleagues for allowing us a preview of their manuscript; Knut Bøe for A. Olsson's thesis and Uta von Borstel for the translation; and Kathy Carlstead, David Shepherdson, Megan Jones and Neville Pillay for their personal inputs to the manuscript.

\section{References}

Adriani, W., Laviola, G., 2002. Spontaneous novelty seeking and amphetamine induced conditioning and sensitisation in adult mice: evidence of dissociation as a function of age at weaning. Neuropsychopharmacology 27, $225-236$.

Agid, O., Shapira, B., Zislin, J., Ritsner, M., Hanin, B., Murad, H., Troudart, T., Bloch, M., Heresco-Levy, U., Lerer, B., 1999. Environment and vulnerability to major psychiatric illness: a case control study of early parental loss in major depression, bipolar disorder and schizophrenia. Mol. Psychiatr. 4, 163-172.

Ames, A., 2000. The Management of Captive Polar Bears, PhD Thesis. Open University.

Apter, R.C., Householder, D.D., 1996. Weaning and weaning management of foals: a review and some recommendations. J. Equine Vet. Sci. 16, 428-435.

Atlanta Fulton County Zoo, 2005. Development of Giant Panda Sociosexual Behavior. Available online at: http:// www.zooatlanta.org/conservation_giant_panda_research_sociosexual.htm.

Barnes, R., Greene, K., Holland, J., Lamm, M., 2002. Management and husbandry of duikers at the Los Angeles Zoo. Zoo Biol. 21, 107-121.

Bashaw, M.J., Tarou, L.R., Maki, T.S., Maple, T.L., 2001. A survey assessment of variables related to stereotypy in captive giraffe and okapi. Appl. Anim. Behav. Sci. 73, 235-247.

Beckett, C.M., Bredenkamp, D., Castle, J., Groothues, C., O’Connor, T.G., The English and Romanian Adoptees Study Team, 2002. Behavior patterns associated with institutional deprivation: a study of children adopted from Romania. Dev. Behav. Pediatr. 23, 297-303.

Benus, R.F., den Daas, S., Koolhaas, J.M., van Oortmerssen, G.A., 1990. Routine formation and flexibility in social and non-social behaviour of aggressive and non-aggressive mice. Behaviour 112, 176-193.

Benus, R.F., Koolhass, J.M., van Oortmerssen, G.A., 1987. Individual differences in behavioural reaction toa changing environment in mice and rats. Behaviour 100, 105-122.

Benus, R.F., Koolhaas, J.M., van Oortmerssen, G.A., 1988. Aggression and adaptation to the light-dark cycle: role of intrinsic and extrinsic control. Physiol. Behav. 43, 131-137.

Bergeron, R., Badnell-Waters, A.J., Lambton, S., Mason, G.J., 2006. Stereotypic oral behaviour in captive ungulates: foraging, diet and gastrointestinal function. In: Mason, G. (Ed.), Stereotypic Behaviour: Fundamentals and Applications to Welfare. CAB International, Wallingford, pp. 19-57. 
Berkson, G., 1967. Abnormal stereotyped motor acts. In: Zubin, J., Hunt, H. (Eds.), Comparative PsychopathologyAnimal and Human. Grune and Stratton, New York.

Berkson, G., 1968. Development of abnormal stereotyped behaviours. Dev. Psychobiol. 1, 118-132.

Berridge, K., Robinson, T., 1998. What is the role of dopamine in reward: hedonic impact, reward learning or incentive salience? Brain Res. Rev. 28, 309-369.

Berry, R.J., 1970. The natural history of the house mouse. Field Stud. 3, 219-262.

Bloomsmith, M., Baker, K., Ross, S., Pazol, K., 2002. The behavioral effects of early rearing experience on captive chimpanzee behavioral development: the juvenile years. Am. J. Primatol. 57 (S1), 54-55.

Bøe, K., 1993. The effect of age at weaning and post-weaning environment on the behaviour of pigs. Acta Agric. Scand. A 43, 173-180.

Bowlby, J., 1969. Attachment. Attachment and Loss, vol. 1. Hogarth Press and the Institute of Psycho-Analysis, London.

Bowlby, J., 1973. Separation: anxiety and anger. Attachment and Loss, vol. 2. Hogarth Press and the Institute of PsychoAnalysis, London.

Bowlby, J., 1980. Loss: sadness and depression. Attachment and Loss, vol. 3. Hogarth Press and the Institute of PsychoAnalysis, London.

Bradshaw, J.W.S., Neville, P.F., Sawyer, D., 1997. Factors affecting pica in the domestic cat. Appl. Anim. Behav. Sci. 52, 373-379.

Brown, G.W., Harris, T., 1978. Social Origins of Depression: a Study of Psychiatric Disorder in Women. Tavistock Publications, London.

Cabib, S., 2006. The neurophysiology of stereotypies II: the role of stress. In: Mason, G.J. (Ed.), Stereotypic Behaviour: Fundamentals and Applications to Welfare. CAB International, Wallingford, pp. 227-255.

Callard, M.D., Bursten, S.N., Price, E.O., 1999. Repetitive backflipping behaviour in captive roof-rats (Rattus rattus) and the effect of cage enrichment. Anim. Welf. 9, 139-152.

Carlson, M., Earls, F., 1997. Psychological and neuroendocrinological sequelae of early social deprivation in institutionalized children in Romania. Ann. N.Y. Acad. Sci. 807, 419-428.

Carlstead, K.J., Mellen, J., Kleiman, D.G., 1999. Black rhinoceros (Diceros bicornis) in US zoos: 1. Individual behavior profiles and their relationship to breeding success. Zoo Biol. 18, 17-34.

Champoux, M., Metz, B., Suomi, S.J., 1991. Behaviour of nursery/peer-reared and mother-reared rhesus monkeys from birth through 2 years of age. Primates 32, 509-514.

Chugani, H.T., Behen, M.E., Muzik, O., Juhász, C., Nagy, F., Chugani, D.C., 2001. Local brain functional activity following early deprivation: a study of postinstitutionalised Romanian orphans. Neuroimage 14, 1290-1301.

Clubb, R., Mason, G., 2002. A review of the welfare of elephants in European zoos. Available online at: http:// www.rspca.org.uk/serlet/ContentServer?pagename=RSPCACampaigns/Elephants/FactsAndReports\&articleid $=1024473728261$. Royal Society for the Prevention of Cruelty to Animals. Horsham, UK.

Clubb, R., Vickery, S.S., Latham, N.R., 2006. Motivation, and motivational explanations for stereotypies. In: Mason, G.J. (Ed.), Stereotypic Behaviour: Fundamentals and Applications to Welfare. CAB International, Wallingford, p. 12.

Cooper, J.J., Ödberg, F.O., Nicol, C.J., 1996. Limitations of the effectiveness of environmental improvement in reducing stereotypic behaviour in bank voles (Clethrionomys glareolus). Appl. Anim. Behav. Sci. 48, 237-248.

Davenport, R.K., Menzel, E.W., 1963. Stereotyped behaviour of the infant chimpanzee. Arch. Gen. Psychiatr. 8, 99-104.

Davidson, H., 2005. The impact of nutrition and feeding practices on equine behaviour and welfare. Available online at: http://www3.vet.upenn.edu/labs/equinebehavior/hvnwkshp/hv02/davidson.htm.

de Passille, A.M., 2001. Sucking motivation and related problems in calves. Appl. Anim. Behav. Sci. 72, $175-187$.

Di Giovanni, M., Valente, M., 1999. Trial and error-attempting to change the lives of socially and environmentally deprived primates. In: Proceedings of the Fourth International Conference on Environmental Enrichment, Edinburgh, Scotland, 28 August-3 September.

Douglas-Hamilton, I., 1972. On the Ecology and Behaviour of the African Elephant, PhD Thesis. University of Oxford, Oxford.

Eisenberg, J.F., McKay, G.M., Jainudeen, M.R., 1971. Reproductive behavior of the Asiatic elephant (Elephas maximus maximus L). Behaviour 38, 193-225.

Ellenbroek, B.A., Cools, A.R., 2002. Early maternal deprivation and prepulse inhibition. The role of the postdeprivation environment. Pharmacol. Biochem. Behav. 73, 177-184.

Ellenbroek, B.A., Riva, M.A., 2003. Early maternal deprivation as an animal model for schizophrenia. Clin. Neurosci. Res. 3, 297-302.

EPA, U., 2004a. Lifecycle Production Phases. Available online at: http://www.epa.gov /agriculture/ag101/dairyphases.html. EPA, U., 2004b. Poultry Production Phases. Available online at: http://www.epa.gov /agriculture/ag101/poultryphases.html. 
European Commission, 2005. EU proposes measures to improve welfare of broiler chickens. Newsletter on food safety, health and consumer policy from the European Commission's Health and Consumer Protection DG. Available online at: http://ec.europa.eu/comm/dgs/ health_consumer/consumervoice/cv_62005_en.pdf.

European Commission Report, 2001. The welfare of animals kept for fur production: report of the scientific committee on health and welfare. Available online at: http://europa.eu.int/comm/food/animal/welfare/international/out67_en.pdf.

Finamore, T.L., Port, R.L., 2000. Developmental stress disrupts habituation but spares prepulse inhibition in young rats. Physiol. Behav. 69, 527-530.

Fisher, L., Ames, E.W., Chisholm, K., Savoie, L., 1997. Problems reported by parents of Romanian orphans adopted to British Columbia. Int. J. Behav. Dev. 20, 67-82.

Flower, F.C., Weary, D.M., 2001. Effects of early separation on the dairy cow and calf: 2. Separation at 1 day and 2 weeks after birth. Appl. Anim. Behav. Sci. 70, 275-284.

Fraser, D., 1978. Observations on the behavioural development of suckling and early-weaned piglets during the first six weeks after birth. Anim. Behav. 26, 22-30.

Fry, J.P., Sharman, D.F., Stephens, D.B., 1981. Cerebral dopamine, apomorphine and oral activity in the neonatal pig. J. Vet. Pharmacol. Ther. 4, 193-207.

Gammie, S.C., Hasen, N.S., Rhodes, J.S., Girard, I., Garland, T., 2003. Predatory aggression, but not maternal or intermale aggression, is associated with high voluntary wheel-running behaviour in mice. Horm. Behav. 44, $209-221$.

Garner, J.P., 1999. The Etiology of Stereotypy, PhD Thesis. University of Oxford, Oxford.

Garner, J.P., 2006. Perseveration and stereotypy—-systems-level insights from clinical psychology. In: Mason, G.J. (Ed.), Stereotypic Animal Behaviour: Fundamentals and Applications to Welfare. CAB International, Wallingford, pp. 121152.

Gill, J.C., Thomson, W., 1956. Observations on the behaviour of suckling pigs. Br. J. Anim. Behav. 4, 46-51.

Gilmer, W.S., McKinney, W.T., 2003. Early experience and depressive disorders: human and non-human primate studies. J. Affect. Disord. 75, 97-113.

Gluck, J.P., Sackett, G.P., 1976. Extinction deficits in socially isolated rhesus monkeys (Macaca mulatta). Dev. Psychol. 12, 173-174.

Goodall, J., Toms, M., 2003. Born to be wild: a conversation with Jane Goodall. Available online at: http://www. newdimensions.org/online-journal/articles/born-to-be-wild.html.

Gould, E., Bres, M., 1986. Regurgitation and reingestion in captive gorillas: description and intervention. Zoo Biol. 5, $241-250$.

Gray, P., 1989. Henry Dwight Chapin: pioneer in the study of institutionalised infants. Bull. Psychon. Soc. $27,85-87$.

Gunnar, M.R., 1999. Overview of research on post-institutionlized children. Paper presented at the Early experience and glucocorticoid network meeting, number 2, Nov 21st. Available online at: http://www.education.umn.edu/icd/ EarlyExp/Public\%2011-21-99.htm.

Haigh, J.C., Stookey, J.M., Bowman, P., Waltz, C., 1997. A comparison of weaning techniques in farmed wapiti (Cervus elaphus). Anim. Welf. 6, 255-264.

Haley, D.B., Bailey, D.W., Stookey, J.M., 2005. The effects of weaning beef calves in two stages on their behavior and growth rate. J. Anim. Sci. 83, 2205-2214.

Hall, F.S., 1998. Social deprivation of neonatal, adolescent and adult rats has distinct neurochemical and behavioral consequences. Crit. Rev. Neurobiol. 12, 129-162.

Hammell, K.L., Metz, J.H.M., Mekking, P., 1988. Sucking behaviour of dairy calves fed milk ad libitum by bucket or teat. Appl. Anim. Behav. Sci. 20, 275-285.

Hansen, S.W., 1992. Stress reactions in farm mink and beech marten in relation to housing and domestication, PhD Thesis. Copenhagen University, Copenhagen.

Harlow, H.F., Schiltz, K.A., Harlow, M.K., 1969. Effects of social isolation on the learning performance of rhesus monkeys. In: Proceedings of the Second International Congress of Primatology, Vol. 1, Karger, S. Basel, pp. 178185.

Harris, M.J., Gonyou, H.W., 1998. Increasing available space in a farrowing crate does not facilitate postural changes or maternal responses in gilts. Appl. Anim. Behav. Sci. 59, 285-296.

Hawkins, P., 2001. Laboratory birds: refinements in husbandry and procedures. Lab. Anim. 35 (Suppl. 1), S1-S163.

Heleski, C., Shelle, A.C., Nielsen, B., Zanella, A.J., 2002. Influence of housing on weanling horse behavior and subsequent welfare. Appl. Anim. Behav. Sci. 78, 291-302.

Hotzel, M.J., Machado, L.C.P., Wolf, F.M., Costa, O.A.D., 2004. Behaviour of sows and piglets reared in intensive outdoor or indoor systems. Appl. Anim. Behav. Sci. 86, 27-39.

Jensen, M.B., 2003. The effects of feeding method, milk allowance and social factors on milk feeding behaviour and cross-sucking in group housed dairy calves. Appl. Anim. Behav. Sci. 80, 191-206. 
Jensen, P., 1986. Observations on the maternal behaviour of free-ranging domestic pigs. Appl. Anim. Behav. Sci. 16, 131142.

Jensen, P., Stangel, G., 1992. Behaviour of piglets during weaning in a semi-natural enclosure. Appl. Anim. Behav. Sci. $33,227-238$.

Jeppesen, L.L., Heller, K.E., Dalsgaard, T., 2000. Effects of early weaning and housing conditions on the development of stereotypies in farmed mink. Appl. Anim. Behav. Sci. 68, 85-92.

Jones, G.H., Hernandez, T.D., Kendall, D.A., Marsden, C.A., Robbins, T.W., 1992. Dopaminergic and serotonergic function following isolation rearing in rats: study of behavioural responses and post mortem and in vivo neurochemistry. Pharmacol. Biochem. Behav. 43, 17-35.

Jones, G.H., Marsden, C.A., Robbins, T.W., 1991. Behavioural rigidity and rule-learning deficits following isolation rearing in the rat: neurochemical correlates. Behav. Brain Res. 43, 35-50.

Jones, M., Pillay, N., 2006. To stereotype or not to stereotype? In: 40th International Congress of the International Society for Applied Ethology, Bristol University.

Kanari, K., Kikusui, T., Takeuchi, Y., Mori, Y., 2005. Multidimensional structure of anxiety-related behavior in earlyweaned rats. Behav. Brain Res. 156, 45-52.

Kehoe, P., Clash, K., Skipsey, K., Shoemaker, W.J., 1996. Brain dopamine response in isolated 10-day-old rats: assessment using D2 binding and dopamine turnover. Pharmacol. Biochem. Behav. 53, 41-49.

Keiper, R.R., 1969. Causal factors of stereotypies in caged birds. Anim. Behav. 17, 114-119.

Kikusui, T., Takeuchi, Y., Mori, Y., 2004. Early weaning induces anxiety and aggression in adult mice. Physiol. Behav. 81, $37-42$.

Kikusui, T., Isaka, Y., Mori, Y., 2005. Early weaning deprives mouse pups of maternal care and decreases their maternal behaviour in adulthood. Behav. Brain Res. 162, 200-206.

King, M., 2005. Number two of seven deadly sins. Horse Talk - April issue. Available online at: http://www.mcfarlanesonline.com/horsetalk-apr05.pdf.

King, N.E., Mellen, J.D., 1994. The effects of early experience on adult copulatory behaviour in zoo-born chimpanzees (Pan troglodytes). Zoo Biol. 13, 51-59.

Kosten, T.A., Zhang, X.Y., Kehoe, P., 2003. Chronic neonatal isolation stress enhances cocaine-induced increases in ventral striatal dopamine levels in rat pups. Dev. Brain Res. 141, 109-116.

Kosten, T.A., Zhang, X.Y., Kehoe, P., 2004. Infant rats with chronic neonatal isolation experience show decreased extracellular serotonin levels in ventral striatum at baseline and in response to cocaine. Dev. Brain Res. 152, 19-24.

Kreger, M.D., Estevez, I., Hatfield, J.S., Gee, G.F., 2004. Effects of rearing treatment on the behavior of captive whooping cranes (Grus americana). Appl. Anim. Behav. Sci. 89, 243-261.

Kreger, M.D., Estevez, I., Hatfield, J.S., Gee, G.F., Clugston, D.A., 2005. The effects of captive rearing on the behavior of newly-released whooping cranes (Grus americana). Appl. Anim. Behav. Sci. 93, 165-178.

Kuhn, C.M., Schanberg, S.M., 1998. Responses to maternal separation: mechanisms and mediators. Int. J. Dev. Neurosci. $16,261-270$.

Latham, N.R., 2004. Refining the role of stereotypies in welfare assessment: stress, general behavioural persistence and early environment in the development of abnormal behaviours, PhD Thesis. University of Oxford, Oxford.

Latham, N.R., Mason, G.J., 2004. From house mouse to mouse house: the behavioural biology of free-living Mus musculus and its implications in the laboratory. Appl. Anim. Behav. Sci. 86, 261-289.

Laule, G., 1993. The use of behavioral management techniques to reduce or eliminate abnormal behavior. AWIC Inf. Center Newslett. 4 (1-2), 8-11.

Laviola, G., Dell'Omo, G., 1997. Precocious weaning and changes in social variables during pre-puberty affect cocaine reinforcing properties in adult mice. Psychobiology 25, 163-170.

Levine, S., 2000. Influence of psychological variables on the activity of the hypothalamic-pituitary-adrenal axis. Eur. J. Pharmacol. 405, 149-160.

Lewis, R.S., Nevison, C.M., Hurst, J.L., 2001. Do laboratory mice chew to escape? In: 35th International Congress of the ISAE. University of California, Davis.

Lewis, M.H., Presti, M.F., Lewis, J.B., Turner, C.A., 2006. The neurobiology of stereotypy 1: environmental complexity. In: Mason, G.J. (Ed.), Stereotypic Animal Behaviour: Fundamentals and Applications to Welfare. CAB International, Wallingford, pp. 190-226.

Llorens Abando, L., Martinez Palou, A., 2006. Main stages in the meat food chain in Europe. Available online at: http:// epp.eurostat.cec.eu.int/cache/ITY_OFFPUB/KS-NN-06-006/EN/KS-NN-06-006-EN.PDF.

Loberg, J., Lidfors, L., 2001. Effect of milkflow rate and presence of a floating nipple on abnormal sucking between dairy calves. Appl. Anim. Behav. Sci. 72, 189-199. 
Mackie, M., 2001. Wool sucking in cats. Available online at: http://www.usask.ca/wcvm/herdmed/applied-ethology/ behaviourproblems/woolcat.html.

MacLean, K., 2003. The impact of institutionalization on child development. Dev. Psychopathol. 15, 853-884.

Maestripieri, D., Carroll, K.A., 1998. Child abuse and neglect: usefulness of the animal data. Psychol. Bull. 123, 211-223.

Main, R.G., Dritz, S.S., Tokach, M.D., Goodband, R.D., Nelssen, J.L., Loughlin, T.M., 2005. Effects of weaning age on postweaning belly-nosing behavior and umbilical lesions in a multi-site production system. J. Swine Health Prod. 13, 259-264.

Mallapur, A., 2005. Managing primates in zoos: lessons from animal behaviour. Curr. Sci. 89, 1214-1219.

Mallapur, A., Choudhury, B.C., 2003. Behavioral abnormalities in captive non-human primates. JAAWS 6, $275-284$.

Mallapur, A., Waran, N., Sinha, A., 2005. Factors influencing the behaviour and welfare of captive lion-tailed macaques in Indian zoos. Appl. Anim. Behav. Sci. 91, 337-353.

Mann, S.P., Sharman, D.F., 1983. Changes associated with early weaning in the activity of tyrosine hydroxylase in the caudate nucleus of the piglet. Comp. Biochem. Physiol. C, Comp. Pharmacol. Toxicol. 74, 267-270.

Manning, A., Dawkins, M.S., 1992. An Introduction to Animal Behaviour. Cambridge University Press, Cambridge.

Margerison, J.K., Preston, T.R., Berry, N., Phillips, C.J.C., 2003. Cross-sucking and other oral behaviours in calves, and their relation to cow suckling and food provision. Appl. Anim. Behav. Sci. 80, 277-286.

Marriner, L.M., Drickamer, L.C., 1994. Factors influencing stereotyped behaviour of primates in a zoo. Zoo Biol. 13, $267-275$.

Martin, J.E., 2002. Early life experiences: activity levels and abnormal behaviours in resocialised chimpanzees. Anim. Welf. 11, 419-436.

Martin, P., 1984. The meaning of weaning. Anim. Behav. 32, 1257-1258.

Mason, G.J., 1991a. Mink stereotypies and early experience. In: Proceedings of the International Congress of the ISAE, Edinburgh, UFAW.

Mason, G.J., 1991b. Stereotypies: a critical review. Anim. Behav. 41, 1015-1037.

Mason, G.J., 1991c. Stereotypies and suffering. Behav. Proc. 25, 103-115.

Mason, G.J., 1992. Individual variation in the stereotypies of caged mink, $\mathrm{PhD}$ Thesis. University of Cambridge, Cambridge.

Mason, G.J., 1995. Tail-biting in mink (Mustela vison) is influenced by age at removal from the mother. Anim. Welf. 3, 305-311.

Mason, G.J., 1996. Early weaning enhances the later development of stereotypy in mink. In: Proceedings of the 30th International Congress of the International Society for Applied Ethology, Guelph, Canada.

Mason, G.J., 2006a. Stereotypic behaviour in captive animals: fundamentals, and implications for welfare and beyond. In: Mason, G.J. (Ed.), Stereotypic Animal Behaviour: Fundamentals and Applications to Welfare. CAB International, Wallingford, pp. 325-356.

Mason, G.J., 2006b. Deprivation stereotypies in human children: the case of the Romanian orphans. In: Mason, G.J. (Ed.), Stereotypic Behaviour: Fundamentals and Applications to Welfare. CAB International, Wallingford, p. 163.

Mason, G.J., 2006c. Are wild-caught animals 'protected' from developing stereotypic behaviour? In: Mason, G.J. (Ed.), Stereotypic Behaviour: Fundamentals and Applications to Welfare. CAB International, Wallingford, p. 196.

Mason, G.J., Latham, N.R., 2004. Can't stop, won't stop: is stereotypy a reliable animal welfare indicator? Anim Welf. 13 (Suppl.), S57-S69.

Mason, G.J., Leipoldt, A.L., de Jonge, G., 1995. Why do female mink with high stereotypy levels have slow-growing offspring? In: Proceedings of the 29th International Congress of the International Society for Applied Ethology, Exeter, UK, 3-5 August, UFAW.

Mason, W.A., Green, P.C., 1962. The effects of social restriction on the behavior of rhesus monkeys. IV. Responses to a novel environment and to an alien species. J. Comp. Physiol. Psychol. 55, 363-368.

Matthews, K., Robbins, T.W., 2003. Early experience as a determinant of adult behavioural responses to reward: the effects of repeated maternal separation in the rat. Neurosci. Biobehav. Rev. 27, 45-55.

McCormick, C.M., Kehoe, P., Mallinson, K., Cecci, L., Frye, C.A., 2002. Neonatal isolation alters stress hormone and mesolimbic dopamine release in juvenile rats. Pharmacol. Biochem. Behav. 73, 77-85.

Meder, A., 1989. Effects of hand-rearing on the behavioral development of infant and juvenile gorillas (Gorilla gorilla gorilla). Dev. Psychobiol. 22, 357-376.

Mellen, J.D., 1992. Effects of early rearing experience on subsequent adult sexual behavior using domestic cats (Felis catus) as a model for small exotic felids. Zoo Biol. 11, 17-32.

Monsen, R.B., 2004. Adopting children. J. Ped. Nurs. 19, 214-215.

Moon-Fanelli, A., 2005. Feline compulsive behavior. Available online at: http://www.tufts.edu/vet/vet_common/pdf/ petinfo/dvm/case_march2005.pdf. 
Moons, C., Laughlin, K., Zanella, A.J., 2005. Effects of short-term maternal separations on weaning stress in foals. Appl. Anim. Behav. Sci. 91, 321-335.

Morris, D., 1987. Catlore. Jonathan Cape, London.

Moss, C.J., Poole, J.H., 1983. Relationships and social structure of African elephants. In: Hinde, R. (Ed.), Primate Social Relationships: an Integrated Approach. Oxford Blackwell Scientific, Oxford.

Nash, L.T., Fritz, J., Alford, P.A., Brent, L., 1999. Variables influencing the origins of diverse abnormal behaviors in a large sample of captive chimpanzees (Pan troglodytes). Am. J. Primatol. 48, 15-29.

Nevison, C.M., Hurst, J.L., Barnard, C.J., 1999. Why do male ICR(CD-1) mice perform bar-related (stereotypic) behaviour? Behav. Proc. 47, 95-111.

Nicol, C.J., Badnell-Waters, A.J., 2005. Suckling behaviour in domestic foals and the development of abnormal oral behaviour. Anim. Behav. 70, 21-29.

Nicol, C.J., Badnell-Waters, A.J., Bice, R., Kelland, A., Wilson, A.D., Harris, P.A., 2005. The effects of diet and weaning method on the behaviour of young horses. Appl. Anim. Behav. Sci. 95, 205-221.

Novak, M.A., Meyer, J.S., Lutz, C., Tiefenbacher, S., 2006. Deprived environments: developmental insights from primatology. In: Mason, G.J. (Ed.), Stereotypic Behaviour: Fundamentals and Applications to Welfare. CAB International, Wallingford, pp. 153-189.

Nuffield Council on Bioethics, 2005. Ethics of research involving animals. Available online at: http://www.nuffieldbioethics.org/go/browseablepublications/ethicsofresearchanimals/report_230.html.

O’Connell, N.E., Beattie, V.E., Sneddon, I.A., Breuer, K., Mercer, J.T., Rance, K.A., Sutcliffe, M.E.M., Edwards, S.A., 2005. Influence of individual predisposition, maternal experience and lactation environment on the responses of pigs to weaning at two different ages. Appl. Anim. Behav. Sci. 90, 219-232.

O’Connor, T.G., Rutter, M., Beckett, C., Keaveny, L., Kreppner, J.M., The English and Romanian Adoptees Study Team, 2000. The effects of global severe privation on cognitive competence: extension and longitudinal follow-up. Child Dev. 71, 376-390.

Ödberg, F.O., 1978. Introduction to abnormal behaviours: Stereotypies. In: Proceedings of the 1st World Congress on Ethology Applied to Zootechnics, Madrid, pp. 475-480.

Olsson, A.C., Rantzer, D., Andersson, M., Svendsen, J., 1990. The effects of different rearing conditions in pigs during the first weeks of life on mother-offspring behaviour, Thesis. Swedish University of Agricultural Sciences.

Orihuela, A., Suárez, E., Vázquez, R., 2004. Effect of restricting suckling on the social bond between ewes and their 10week-old lambs. Livestock Prod. Sci. 87, 259-264.

Perré, Y., Wauters, A.M., Richard-Yris, M.A., 2002. Influence of mothering on emotional and social reactivity of domestic pullets. Appl. Anim. Behav. Sci. 75, 133-146.

Petersen, V., 1994. The development of feeding and investigatory behaviour in free-ranging domestic pigs during their first 18 weeks of life. Appl. Anim. Behav. Sci. 42, 87-98.

Poeggel, G., Nowicki, L., Braun, K., 2003. Early social deprivation alters monaminargic afferents in the orbital prefrontal cortex of Octodon degus. Neuroscience 116, 617-620.

Poletto, R., Steibel, J.P., Siegford, J.M., Zanella, A.J., 2006. Effects of early weaning and social isolation on the expression of glucocorticoid and mineralocorticoid receptor and 11b-hydroxysteroid dehydeogenase 1 and 2 mRNAs in the frontal cortex and hippocampus of piglets. Brain Res. 1067, 36-42.

Pötzsch, C.J., Lewis, K., Nicol, C.J., Green, L.E., 2001. A cross-sectional study of the prevalence of vent pecking in laying hens in alternative systems and its associations with feather pecking, management and disease. Appl. Anim. Behav. Sci. 74, 259-272.

Price, E.O., Harris, J.E., Borgwardt, R.E., Sween, M.L., Connor, J.M., 2003. Fenceline contact of beef calves with their dams at weaning reduces the negative effects of separation on behavior and growth rate. J. Anim. Sci. 81, $116-121$.

Pryce, C.R., Ruedi-Bettschen, D., Dettling, A.C., Weston, A., Russig, G., Ferger, B., Feldon, J., 2005. Long-term effects of early-life environmental manipulations in rodents and primates: potential animal models in depression research. Neurosci. Biobehav. Rev. 29, 649-674.

Reinhardt, V., 2002. Artificial weaning of calves: benefits and costs. JAAWS 5, 251-255.

Reinhardt, V., Reinhardt, A., 1981. Natural sucking performance and age of weaning in zebu cattle (Bos indicus). J. Agric. Sci. 96, 309-312.

Reite, M., Kaeming, K., Boccia, M.L., 1989. Maternal separation in bonnet monkey infants: altered attachment and social support. Child Dev. 60, 473-480.

Roden, C., Wechsler, B., 1998. A comparison of domestic chicks reared with or without a hen in enriched pens. Appl. Anim. Behav. Sci. 55, 317-326.

Rutter, M., O'Connor, T.G., The English and Romanian Adoptees Study Team, 2004. Are there biological programming effects for psychological development? Findings from a study of Romanian adoptees. Dev. Psychol. 40, 81-94. 
Ryan, S., Thompson, S.D., Roth, A.M., Gold, K.C., 2002. Effects of hand-rearing on the reproductive success of western lowland gorillas in North America. Zoo Biol. 21, 389-401.

Rybiski-Tarou, L., Bloomsmith, M.A., Maple, T.L., 2005. Survey of stereotypic behavior in Prosimians. Am. J. Primatol. 65, 181-196.

Sackett, G.P., Novak, M.F.S.X., Kroeker, R., 1999. Early experience effects on adaptive behaviour. Ment. Retard. Dev. Disabil. Res. Rev. 5, 30-40.

Sanchez, M.M., Ladd, C.O., Plotsky, P.M., 2001. Early adverse experience as a developmental risk factor for later psychopathology: evidence from rodent and primate models. Dev. Psychopathol. 13, 419-449.

Sandson, J., Albert, M.L., 1984. Varieties of perseveration. Neuropsychologia 22, 715-732.

Schmid, R., 2004. The influence of the breeding method on the behaviour of adult African grey parrots, inaugural dissertation. Universitat Bern, Switzerland.

Schoenecker, B., Heller, K.E., Freimanis, T., 2000. Development of stereotypies and polydipsia in wild-caught bank voles (Clethrionomys glareolus) and their laboratory bred offspring. Is polydipsia a symptom of diabetes mellitus? Appl. Anim. Behav. Sci. 68, 349-357.

Schradin, C., Pillay, N., 2003. Paternal care in the social and diurnal striped mouse (Rhabdomys pumilio): laboratory and field evidence. J. Comp. Psychol. 117, 317-324.

Shapiro, S.J., Lee-Parritz, D.E., Taylor, L.L., Watson, L., Bloomsmith, M.A., Petto, A., 1994. Behavioural management of specific pathogen-free rhesus macaques: group formation, reproduction and parental competence. Lab. Anim. Sci. 44, 229-234.

Sharman, D.F., Mann, S.P., Fry, J.P., Banns, H., Stephens, D.B., 1982. Cerebral dopamine metabolism and stereotyped behaviour in early-weaned piglets. Neuroscience 7, 1937-1944.

Sih, A., Bell, A., Johnson, J.C., 2004. Behavioral syndromes: an ecological and evolutionary overview. TREE 19, 372378.

Slater, L., 2004. Monkey love: Harry Harlow's classic primate experiments suggest that to understand the human heart you must be willing to break it. Available online at: http://www.boston.com/news/globe/ideas/articles/2004/03/21/ monkey_love/.

Sørensen, G., Randrup, A., 1986. Possible protective value of severe psychopathology against lethal effects of an unfavourable milieu. Stress Med. 2, 103-105.

Spear, L.P., Scalzo, F.M., 1985. Ontogenetic alterations in the effects of food and/or maternal deprivation on 5-HT, 5HIAA and 5-HIAA/5-HT ratios (Abstract only). Dev. Brain Res. 18, 143-157.

Spijkerman, R., Dienske, H., van Hooff, J.A.R.A.M., Jens, W., 1994. Causes of body rocking in chimpanzees (Pan troglodytes). Anim. Welf. 3, 193-211.

Spitz, R., 1945. Hospitalism. An inquiry into the genesis of psychiatric conditions in early childhood. Psychoanal. Study Child. 1, 53-74.

Spitz, R., 1946. Anaclytic depression. Psychoanal. Study Child. 2, 313-342.

Stolba, A., Wood-Gush, D.G.M., 1989. The behaviour of pigs in a semi-natural environment. Anim. Prod. 48, 419-425.

Straw, B.E., Bartlett, P., 2001. Flank or belly nosing in weaned pigs. J. Swine Health Prod. 9.

Stroman, H.R., Slaughter, L.M., 1972. The care and breeding of the pygmy hippopotamus, Chereopsis liberiensis, in captivity. Int. Zoo Yearbook 12, 126-131.

Sukumar, R., 1989. The Asian Elephant: Ecology and Management. Cambridge University Press, Cambridge.

Sumner, B.E.H., Lawrence, A.B., Jarvis, S., Calvert, S.K., Stevenson, J., Farnworth, M.T., Croy, I., Douglas, A.J., Russell, J.A., Seckl, J.R., 2002. Enduring behavioural and neural effects of early versus late weaning in pigs. Stress (Suppl. 5), 105.

Toates, F., 2004. Cognition, motivation, emotion and action: a dynamic and vulnerable interdependence. Appl. Anim. Behav. Sci. 86, 173-204.

Torrey, S., Widowski, T.M., 2004. Effect of drinker type and sound stimuli on early-weaned pig performance and behavior. J. Anim. Sci. 82, 2105-2114.

Troster, H., 1994. Prevalence and functions of stereotyped behaviors in non-handicapped children in residential care. J. Abnorm. Child Psychol. 22, 79-97.

Tuyttens, F.A.M., 2005. The importance of straw for pig and cattle welfare: a review. Appl. Anim. Behav. Sci. 92, 261-282.

U.S. Department of Agriculture National Agricultural Statistics Service, 2005a. Chickens and eggs: 2004 Summary. Available online at: http://usda.mannlib.cornell.edu/reports/nassr/poultry/pec-bbl/lyegan05.pdf.

U.S. Department of Agriculture National Agricultural Statistics Service, 2005b. Livestock Slaughter: 2004 Annual Summary. Available online at: http://usda.mannlib.cornell.edu/reports/nassr/livestock/pls-bban/lsan0305.pdf.

U.S. Department of Agriculture National Agricultural Statistics Service, 2005c. Poultry Slaughter: 2004 Annual Summary. Available online at: http://usda.mannlib.cornell.edu/reports/nassr/poultry/ppy-bban/pslaan05.pdf. 
Van Keulen-Kromhout, G.M., 1978. Zoo enclosures for bears Ursidae: their influence on captive behaviour and reproduction. Int. Zoo Yearbook 18, 177-186.

Vazquez, D.M., Lopez, J.F., Van Hoers, H., Watson, S.J., Levine, S., 2000. Maternal deprivation regulates serotonin 1A and $2 \mathrm{~A}$ receptors in the infant rat. Brain Res. 855, 76-82.

Veissier, I., de Passille, A.M., Despres, G., Rushen, J., Charpentier, I., Ramirez de la Fe, A.R., Pradel, P., 2002. Does nutritive and non-nutritive sucking reduce other oral behaviors and stimulate rest in calves? J. Anim. Sci. 80, 25742587.

Veissier, I., Lamy, D., Le Neindre, P., 1990. Social behaviour in domestic beef cattle when yearling calves are left with the cows for the next calving. Appl. Anim. Behav. Sci. 27, 193-200.

Waiblinger, E., Konig, B., 2004. Refinement of gerbil housing and husbandry in the lab. Alt. Lab. Anim. 32, $163-169$.

Waters, A.J., Nicol, C.J., French, N.P., 2002. Factors influencing the development of stereotypic and redirected behaviours in young horses: findings of a four year prospective epidemiological study. Equine Vet. J. 34, 572-579.

Weary, D.M., Appleby, M.C., Fraser, D., 1999. Responses of piglets to early separation from the sow. Appl. Anim. Behav. Sci. 63, 289-300.

Widowski, T.M., Torrey, S., Bench, C.J., Gonyou, H.W., 2008. Development of ingestive behaviour and the relationship to belly nosing in early-weaned piglets. Appl. Anim. Behav. Sci. 110, 109-127.

Wiedenmayer, C., 1997. Causation of the ontogenic development of stereotypic digging in gerbils. Anim. Behav. 53, 461470.

Wielebnowski, N.C., Fletchall, N., Carlstead, K., Busso, J.M., Brown, J.L., 2002. Noninvasive assessment of adrenal activity associated with husbandry and behavioral factors in the North American clouded leopard population. Zoo Biol. 21, 77-98.

Worobec, E.K., Duncan, I.J.H., Widowski, T.M., 1999. The effects of weaning at 7, 14 and 28 days on piglet behaviour. Appl. Anim. Behav. Sci. 62, 173-182.

Würbel, H., 2001. Ideal homes? Housing effects of rodent brain and behaviour. Trends Neurosci. 24, $207-211$.

Würbel, H., 2006a. Developmental plasticity and animal welfare: adaptive plasticity, phenotypic mismatch or pathology? In: Proceedings of the 40th International Congress of the ISAE, University of Bristol.

Würbel, H., 2006b. Behavioural pathology—attempt at a biologically meaningful definition. In: Mason, G.J. (Ed.), Stereotypic Behaviour: Fundamentals and Applications to Welfare. CAB International, Wallingford, p. 15.

Würbel, H., 2006c. The motivational basis of caged rodents' stereotypies. In: Mason, G.J. (Ed.), Stereotypic Behaviour: Fundamentals and Applications to Welfare. CAB International, Wallingford, pp. 86-120.

Würbel, H., Stauffacher, M., 1997. Age and weight at weaning affects corticosterone levels and development of stereotypies in ICR mice. Anim. Behav. 53, 891-900.

Würbel, H., Stauffacher, M., 1998. Physical condition at weaning affects exploratory behaviour and stereotypy development in laboratory mice. Behav. Proc. 43, 61-69.

Würbel, H., Stauffacher, M., Holst, D., 1996. Stereotypies in laboratory mice-Quantative and qualitative description of the ontogeny of wire-gnawing and jumping in Zur:ICR and Zur:ICR nu. Ethology 102, 371-385. 